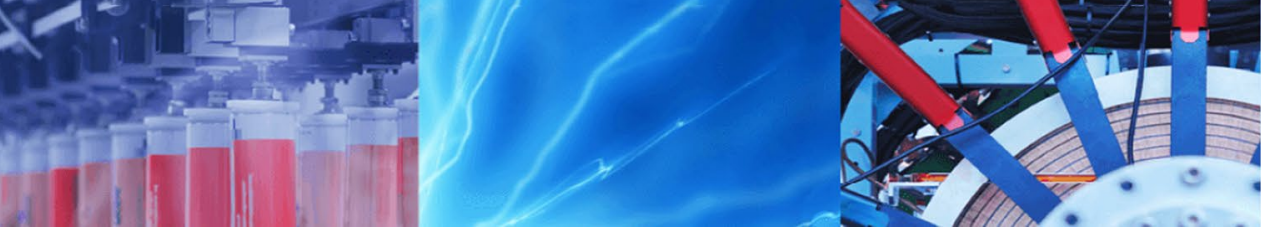

Research Article

\title{
A 35-year meteorological drought analysis in the Caribbean Region: case study of the small island state of Trinidad and Tobago
}

\author{
Sharlene L. Beharry ${ }^{1}$ Donald Gabriels ${ }^{2} \cdot$ Deyanira Lobo $^{3} \cdot$ Ricardo M. Clarke $^{1}$
}

(c) Springer Nature Switzerland AG 2019

\begin{abstract}
Small island states are vulnerable to changes in extreme weather events. In order to mitigate the effects of these events such as droughts, the understanding of the patterns of meteorological droughts is one of the first steps. This study aims to build a baseline scenario of meteorological droughts using the Standardized Precipitation Index (SPI) for the southernmost Caribbean islands of Trinidad and Tobago. Fourteen precipitation datasets, for the period 1980 to 2014, were analyzed to identify and assess temporal and spatial variations of droughts. The relevant SPI temporal intervals for the area are 2-M (Month), 5-M Dry and 7-M Wet corresponding to the dry and wet seasons and 12-M. Meteorological droughts were found to be heterogeneous in occurrence, magnitude, severity and frequency across Trinidad. Meteorological droughts were identified in the following years; for the 2-M, 1987 and 1989; for the long term, 12-M in 1993, 2001 and 2010; seasonally, for 5-M Dry, 2014 and for 7-M Wet, 2010. The observed decrease (increase) in frequency of dry events may have a positive (negative) effect on the Hollis (Navet) dam. Statistically significant trends were observed for the 12-M SPI with magnitudes ranging from -0.06 to 0.04 per year and these were larger than the 2-M SPI trends, with changes between -0.03 and 0.02 per year. For the first time, three areas of similar drought variability were identified for north and central Trinidad. These results highlight the variations of drought characteristics over a small island, the possible adverse effects on surface water reservoirs and provide impetus for more island specific studies.
\end{abstract}

Keywords Standardized Precipitation Index · Drought · Trinidad and Tobago $\cdot$ Water resources $\cdot$ Rainfall $\cdot$ Dry events

\section{Introduction}

Floods and droughts are natural phenomena but these extreme weather events are becoming more severe and less predictable [1] which leads to the uncertainty of the occurrence of these events. Changing patterns of floods and droughts in small islands states, such as those in the Caribbean, may have adverse effects on the available water resources and agriculture. In addition, damages to infrastructure associated with these events may result in an overall high cost to the state. The Intergovernmental Panel on Climate Change (IPCC) 5th Assessment Report,
Small Islands Chapter, noted that there are advances at the regional scale rather than country specific and stated that there is a "need to acknowledge the heterogeneity and complexity of small island states and territories" [2]. In the management of droughts the assessment of spatial and temporal variability is important [3]. This assessment maybe used to create a drought baseline that describes the nature of the historical droughts' frequency of occurrence, and the temporal and spatial patterns. Due to limited understanding of drought patterns in the Caribbean and the need to manage droughts in these vulnerable island states, this study thus focuses on the southernmost

Sharlene L. Beharry, sharlenelata@yahoo.com; Donald Gabriels, donaldgabriels@gmail.com; Deyanira Lobo, lobodeyanira@ gmail.com; Ricardo M. Clarke, ricardo.clarke@sta.uwi.edu | 'Department of Physics, The University of the West Indies, St Augustine, Trinidad and Tobago. ${ }^{2}$ Department of Soil Management, Ghent University, Ghent, Belgium. ${ }^{3}$ Agronomy Faculty, Universidad Central de Venezuela, Caracas, Venezuela. 
small islands of the Caribbean, the Republic of Trinidad and Tobago and assesses the patterns of meteorological droughts over a 35-year period.

The literature on droughts in the Caribbean is limited and it was recognized that there was a need to monitor and forecast droughts at a regional and national level. As a result, the Caribbean Drought and Precipitation Monitoring Network (CDPMN) and the Caribbean Region Climate Outlook Forum (CariCOF) were established in 2009 and 1998, respectively. The Food and Agriculture Organization of the United Nations (FAO) reported that the 2009-2010 drought in the Caribbean was the worst in over 40 years and this led to significant water shortages across the region which resulted in agricultural and other losses from key economic sectors [4]. In Trinidad and Tobago, during that drought, food prices increased by $6.9 \%$ in March 2010 compared with $6.3 \%$ in February and $2.7 \%$ in January; the cattle livestock was affected by diseases; and two of the islands' reservoirs recorded lower than average levels [5]. Restrictions on water use in the dry season are normally implemented by the Trinidad and Tobago Water and Sewerage Authority (WASA) [6-8].

Acknowledging that precipitation in the Caribbean region is not homogeneous, Jury et al. [9] utilized factor analysis and divided the islands of the Caribbean into four different groups. Noteworthy is the omission of Trinidad and Tobago in that study. Stephenson et al. [10] extended the study area of Jury et al. [9] and included Trinidad and Tobago into a new group. The new group included Curacao, Guyana, Suriname and Trinidad and Tobago. Thus indicating that the rainfall patterns in Trinidad and Tobago maybe different from the other small islands in the Caribbean. Research on Trinidad's precipitation patterns showed that the rainfall trends differ in the north and south regions of Trinidad [11]. Additionally, investigations for trends, jumps, cycles and extreme precipitation are shown in Singh [12], Stone [13], Beharry et al. [14, 15]. Furthermore, climate projections have shown Trinidad and Tobago, being part of the Southern Caribbean, to be characterized by less intense rainfall, more dry days [16] and a drying trend with warmer conditions [17]. However, there are no robust studies on the historical droughts for Trinidad and Tobago. We therefore selected Trinidad and Tobago as the case study with an attempt to fill this gap on the understanding of the nature of historical droughts.

In the classification of meteorological droughts, one of the most widely used index is the standardized precipitation index (SPI). This index was developed based on the fact that the deficit of precipitation has impacts on groundwater, reservoir storage, soil moisture and stream flow [18]. The SPI has been applied to many different countries which include Brazil [19], China [20, 21]; Ethiopia [22]; Greece [23]; India [24, 25]; Italy [26]; Iran [3, 27, 28]; and Sri
Lanka [29]. The SPI is flexible such that various temporal intervals can be estimated as well as the different categories of drought. One other similar index is the Standardized Precipitation and Evapotranspiration Index (SPEI) which requires both temperature and precipitation as input data [30]. In the Caribbean, the CDPMN utilizes different indices in their monitoring exercises such as the SPI, the Palmer Drought Severity index (PDSI) and the Crop Moisture Index (CMI) [31]. The PDSI requires both temperature and precipitation [32] and the CMI provides information on agricultural droughts only [33]. The SPI requires precipitation as the only input parameter and there is flexibility in the time scale use in analyzing both wet and dry events.

In Trinidad data availability for rainfall and temperature is limited, however spatially there are more precipitation stations than temperature. Thus, with the aim to assess the spatial variations of droughts in Trinidad and due to the availability of the input data as well as the flexibility of the different time intervals, the SPI was identified for application in this study.

Based on the dry spell and meteorological drought policy for Trinidad and Tobago, the most relevant temporal intervals for the country are 2-months (2-M), 5-months (5-M), 7-months (7-M) and 12-months (12-M) SPIs [34]. It has been noted that the 2-M SPI can be used to determine the onset of meteorological drought and for long term droughts the 12-M SPI is suitable [34]. For the seasonal assessment the 5-M and 7-M SPIs are utilized. The objective of this study is to assess meteorological droughts using SPI at different time scales relevant to the climate of Trinidad and Tobago by considering historical precipitation data from 13 stations over the northern and central regions of Trinidad and one station in the smaller island of Tobago. Our assessment includes the identification of dry events for 2-M SPI, seasonal SPIs and 12-M SPI, the analysis of the frequency of dry and wet events, the determination of temporal trends of the SPIs, and the identification of areas with similar drought variability for the 12-M SPI. The results of this study will be the first detailed analysis of Trinidad's meteorological droughts.

We introduce the study area, precipitation data and limitations of the study in Sect. 2 and outline the methodology in Sect. 3. In Sect. 4, the results for the spatio-temporal variations and trends of the meteorological droughts are presented. Section 5 discusses the results and concluding remarks are given in Sect. 6.

\section{Study area and data}

The study area is the Republic of Trinidad and Tobago, a two island state located between $10^{\circ} \mathrm{N}$ and $11.5^{\circ} \mathrm{N}$ latitude and between $60^{\circ} \mathrm{W}$ and $62^{\circ} \mathrm{W}$ longitude in the 


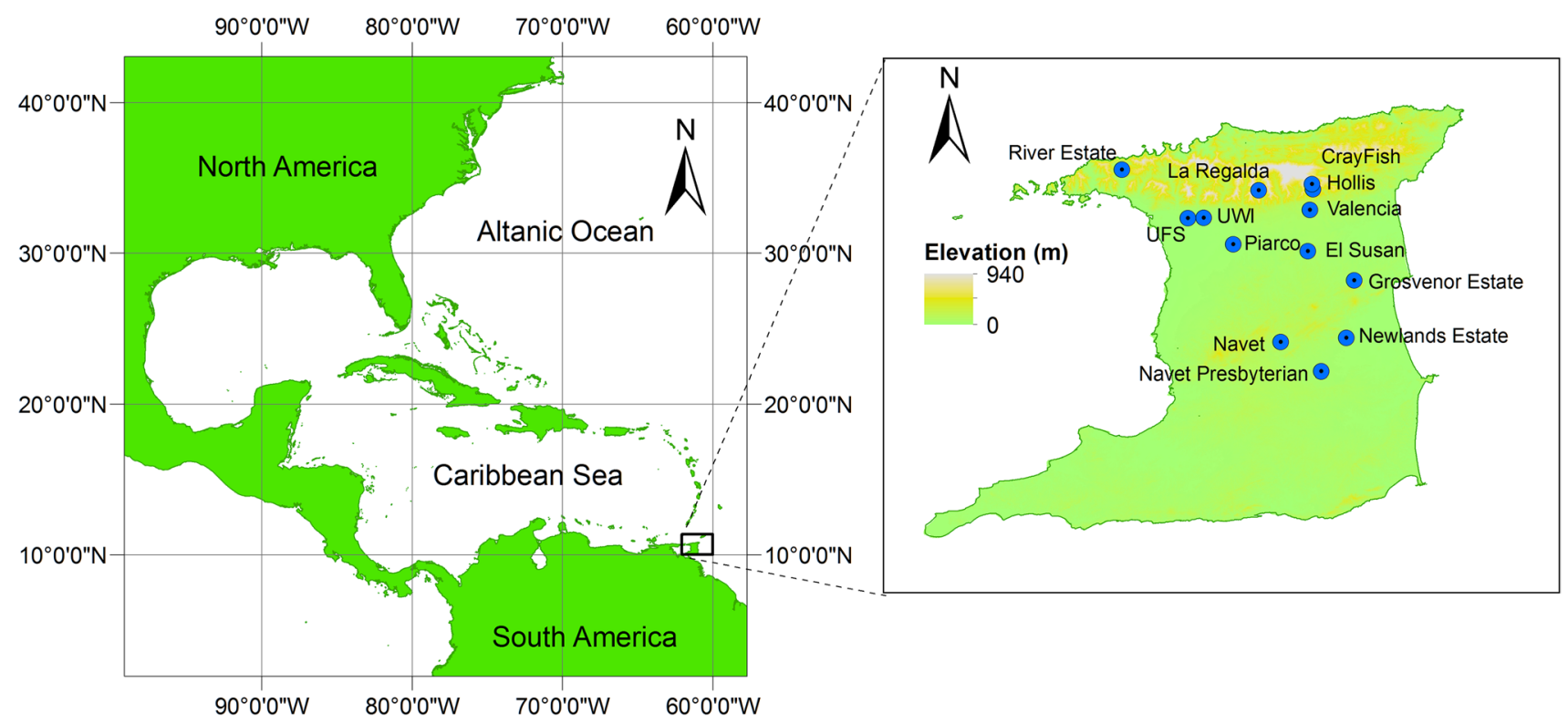

Fig. 1 Location of Trinidad in the Caribbean including the thirteen rainfall stations considered in this study

Caribbean region off the north eastern point of the South America country of Venezuela (Fig. 1 ). The total surface area of Trinidad and Tobago is $5126 \mathrm{~km}^{2}$, with Trinidad, the larger island spanning an area of $4826 \mathrm{~km}^{2}$ while Tobago covers $300 \mathrm{~km}^{2}$ [35].

In these islands there exist two distinct seasons: a dry season during January to May, which is not entirely dry and a wet season, June to December. These seasons are classified by the tropical maritime and modified moist equatorial, respectively [36]. During the wet season, there is usually a dry spell, locally referred as 'Petit Careme', which occurs sometime during September and October [37].

The data for fourteen monthly rainfall stations were obtained from the Water Resources Agency of Trinidad and Tobago (WRA), the Meteorological Service of Trinidad and Tobago (MET), and The University of the West Indies, St Augustine (UWI). There was only one dataset available for the relatively smaller island of Tobago. For Trinidad, thirteen stations represent a comprehensive coverage of the northern and central regions, inclusive of the three major dams; Navet, Arena and Hollis. The Navet and Hollis rainfall stations are situated the respective dam sites. The lengths of the time period of the data sets varied, however for comparison the common time period of 1980 to 2014 for all stations was used in this study. Hence, these years which represented a 35-year period, were extracted and investigated. There were six stations with complete records of rainfall and eight with $<10 \%$ missing data. Further details of the monthly rainfall data used in this study include the names of the stations, the percentage of missing data for each station, the geographical locations and the source of the data (Table 1). The locations of the 13 stations for Trinidad are shown in Fig. 1.

\subsection{Limitations}

There are a few limitations to this study which include coverage of the northern and central regions of Trinidad and Tobago only by the 14 precipitation stations (Fig. 1). The results presented therefore were not representative of the southern part of the island of Trinidad.

Another limitation was that some of the datasets were incomplete, as seen in the percent of missing data (Table 1). These incomplete datasets present a challenge in that the months with missing data resulted in erroneous index values which may not be representative of the actual condition. Thus, these erroneous index values were falsely identified as meteorological droughts. The details of how the months with missing data were addressed are outlined in Sect. 4.2.

The choice of the analytical tool based on the available data also posed a limitation in the use of the results of this study. There are many strengths of the SPI, however, it is not suitable for climate change analysis because temperature is not an input parameter [18]. The SPEI has the same versatility as the SPI in the identification of the meteorological droughts and the SPEI generates a similar output as the SPI as well as includes the temperature component [30]. Thus, allowing the results of the SPEI to be used in climate change analyses. In our study, unfortunately 
Table 1 Rainfall stations with geographical locations, the percentage of missing data and the source of data

\begin{tabular}{|c|c|c|c|c|c|}
\hline $\begin{array}{l}\text { Station } \\
\text { number }\end{array}$ & Station name & $\begin{array}{l}\text { Percent of } \\
\text { missing data }\end{array}$ & Latitude, N & Longitude, W & Data source \\
\hline 1 & UWI & 0.0 & $10^{\circ} 38^{\prime} 13^{\prime \prime}$ & $61^{\circ} 23^{\prime} 59^{\prime \prime}$ & UWI \\
\hline 2 & Piarco & 0.0 & $10^{\circ} 35^{\prime} 14^{\prime \prime}$ & $61^{\circ} 20^{\prime} 41^{\prime \prime}$ & MET \\
\hline 3 & River Estate & 5.6 & $10^{\circ} 43^{\prime} 39^{\prime \prime}$ & $61^{\circ} 33^{\prime} 15^{\prime \prime}$ & WRA \\
\hline 4 & Grosvenor Estate & 1.7 & $10^{\circ} 31^{\prime} 07^{\prime \prime}$ & $61^{\circ} 06^{\prime} 59^{\prime \prime}$ & WRA \\
\hline 5 & Newlands Estate & 2.4 & $10^{\circ} 24^{\prime} 41^{\prime \prime}$ & $61^{\circ} 07^{\prime} 56^{\prime \prime}$ & WRA \\
\hline 6 & Navet Presbyterian & 1.6 & $10^{\circ} 20^{\prime} 57^{\prime \prime}$ & $61^{\circ} 10^{\prime} 47^{\prime \prime}$ & WRA \\
\hline 7 & Valencia Range & 0.2 & $10^{\circ} 39^{\prime} 02^{\prime \prime}$ & $61^{\circ} 11^{\prime} 57^{\prime \prime}$ & WRA \\
\hline 8 & Hollis (Dam) & 0.0 & $10^{\circ} 41^{\prime} 08^{\prime \prime}$ & $61^{\circ} 11^{\prime} 41^{\prime \prime}$ & WRA \\
\hline 9 & Navet (Dam) & 0.7 & $10^{\circ} 24^{\prime} 05^{\prime \prime}$ & $61^{\circ} 15^{\prime} 18^{\prime \prime}$ & WRA \\
\hline 10 & Crayfish & 2.3 & $10^{\circ} 41^{\prime} 55^{\prime \prime}$ & $61^{\circ} 11^{\prime} 43^{\prime \prime}$ & WRA \\
\hline 11 & UFS & 0.0 & $10^{\circ} 38^{\prime} 12^{\prime \prime}$ & $61^{\circ} 25^{\prime} 47^{\prime \prime}$ & UWI \\
\hline 12 & El Susan & 3.8 & $10^{\circ} 34^{\prime} 24^{\prime \prime}$ & $61^{\circ} 12^{\prime} 14^{\prime \prime}$ & WRA \\
\hline 13 & La Regalada & 0.0 & $10^{\circ} 41^{\prime} 15^{\prime \prime}$ & $61^{\circ} 17^{\prime} 46^{\prime \prime}$ & WRA \\
\hline 14 & Crown Point, Tobago & 0.0 & $11^{\circ} 08^{\prime} 54^{\prime \prime}$ & $60^{\circ} 25^{\prime} 25^{\prime \prime}$ & MET \\
\hline
\end{tabular}

temperature data were unavailable for most of the stations. That is, out of the fourteen stations, there were only three temperature datasets. These were at the Piarco, the University Field Station (UFS) and Crown Point locations. In spite of the limitation of the temperature datasets, it has been reported in regions where the temperature interannual variability is not very high, the results of the SPI and SPEI do not vary [3]. Hence, given the availability of data the SPI was the chosen tool to analyze meteorological droughts in this study.

\section{Method}

In this section the data quality checks, the different statistical trend tests applied, the computation of the standardized precipitation index and spatial analysis using the principal component analysis are described and presented. A summary of the methods applied in this study is presented in Fig. 2.

\subsection{Data quality checks}

The monthly rainfall datasets which comprise of thirteen stations for Trinidad and one for Tobago were examined for negative rainfall values, missing data and outliers. There were no negative rainfall values in any of the datasets. Of the fourteen time series analyzed, six were with complete records, five for Trinidad and one for Tobago. Ideally, datasets should be $100 \%$ complete [38], however in order to obtain a better spatial representation of rainfall over the islands, a maximum of $10 \%$ missing data which has been

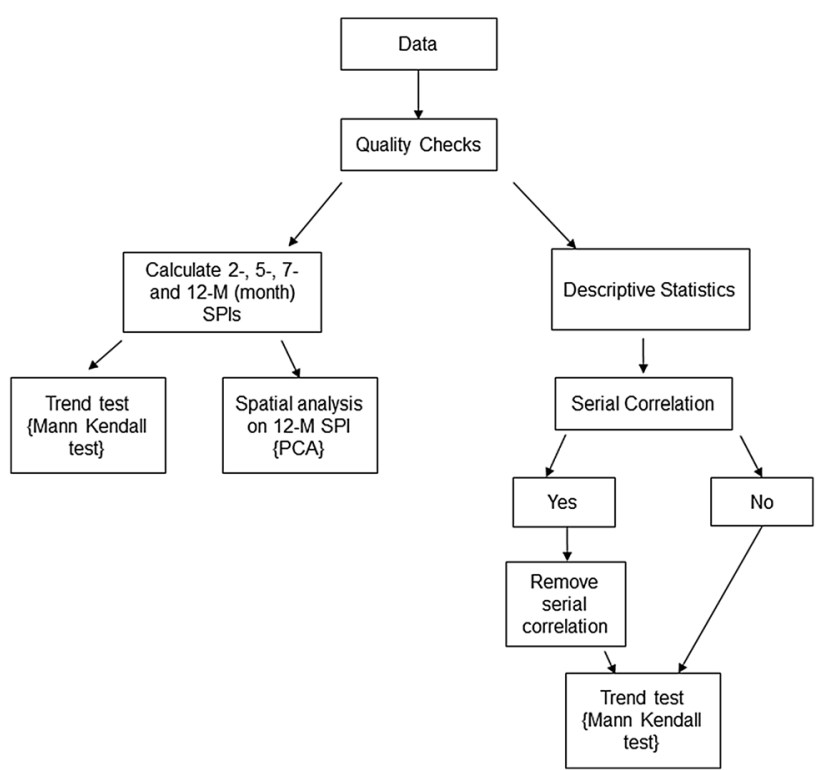

Fig. 2 Flow chart showing steps and the methods applied in this study

acceptable in the literature $[18,39,40]$ was adopted for this study. Missing data were not filled so as to give a true representation of the precipitation and were flagged by -9999 in the input data precipitation time series.

\subsection{Descriptive statistics and trend test}

Subsequent to the quality checks, descriptive statistics such as mean, standard deviation (SD) and coefficient of variation (CV) were computed for the monthly, annual and seasonal average rainfall. The data were grouped into sets based on the seasons, 5 months; January to May for the 
dry season and 7 months; June to December for the wet/ rainy season.

The monthly, seasonal and annual time series were then investigated for serial correlation, and corrected using the trend free pre-whitening process (TFPW) [41-43]. These datasets were then analyzed for statistical significant monotonic trends using the Mann-Kendall test and the Sen's slope estimator which have also been applied by [43-45].

The Mann-Kendall test statistics, S (Eq. 1) was used to determine if the null hypothesis is to be accepted or not [46]. The null hypothesis states that there is no correlation between the variables $\left(x_{1}, \ldots, x_{n}\right)$ which are independent randomly distributed variables and the alternative hypothesis $\mathrm{H}_{\mathrm{a}}$, states there is a monotonic trend.

$S=\sum_{k=1}^{n-1} \sum_{j=k+1}^{n} \operatorname{sgn}\left(x_{j}-x_{k}\right)$

If the test statistic is positive, then the trend is upward or increasing. Vice versa, if the test statistic is negative, then the trend is downward or decreasing. The sign function (sgn) was determined by [46], as shown in Eq. 2

$\operatorname{sgn}\left(x_{j}-x_{k}\right)= \begin{cases}+1 & \text { if }\left(x_{j}-x_{k}\right)>0 \\ 0 & \text { if }\left(x_{j}-x_{k}\right)=0 \\ -1 & \text { if }\left(x_{j}-x_{k}\right)<0\end{cases}$

For $n \geq 10$, where $n$ is the number of data points, the test statistic is distributed asymptotically normal and distributed with a mean equal to zero and the variance calculated using Eq. 3 [47]

Variance $(S)=\frac{\left[n(n-1)(2 n+5)-\sum_{t} t(t-1)(2 t+5)\right]}{18}$,

In Eq. 3, $\mathrm{t}$ takes into consideration ties that may occur. In addition, the standard normal variate $\mathrm{Z}$ is computed using [47], Eq. 4.

$Z= \begin{cases}\frac{S-1}{\sqrt{\text { Variance(S) }}} & \text { if } S>0 \\ 0 & \text { if } S=0 \\ \frac{S+1}{\sqrt{\text { Variance(S) }}} & \text { if } S<0\end{cases}$

At the $95 \%$ significant level or $a=0.05$, for a two tail trend test the null hypothesis is accepted if $|Z| \leq \frac{Z_{\alpha}}{2}$.

Sen's slope estimator was used to estimate the slope of a linear trend [48]. It involves the calculation of the median of $n$ values as shown in Eq. 5 [47],

$Q_{i}=\frac{x_{j}=x_{k}}{j-k}$ for all $i<j$ and $i=1,2, \ldots,(n-1) ; j=2,3, \ldots, n$.

In addition, the calculated SPI time series were analyzed using the Mann-Kendall test which has been successfully used on SPI time series $[24,26,49]$.

\subsection{Assessment of dry and wet events using Standardized Precipitation Index}

The quality controlled data were evaluated for meteorological droughts (events of dryness) and events of wetness using the standardized precipitation index (SPI). The SPI calculation is site specific which is based on the historical long-term records of precipitation. WMO [18] summarizes the calculation as fitting the long-term record to a probability distribution, which is then transformed into a normal distribution so that the mean SPI for the location and desired period is zero.

For each station, the following method based on Edwards and Mckee [50] was applied to the rainfall data. Each precipitation dataset was fitted to the following gamma distribution function

$g(x)=\frac{1}{\beta^{\alpha} \Gamma(\alpha)} x^{\alpha-1} e^{-x / \beta}$ for $x>0$

where $\alpha>0$ is a shape parameter, $\beta>0$ is a scale parameter, $x$ is the rainfall amount in $\mathrm{mm}$ and $\Gamma(\alpha)=\int_{0}^{\infty} x^{\alpha-1} e^{-x} d x, \Gamma(\alpha)$ is the gamma function.

The alpha and beta parameters of the gamma probability density function are estimated for each station, for each time scale of interest and for each month of the year using

$\hat{\alpha}=\frac{1}{4 A}\left(1+\sqrt{\frac{4 A}{3}}\right)$

$\hat{\beta}=\frac{\bar{x}}{\hat{\alpha}}$

where $\bar{x}$ is the mean rainfall and for $n$ observations

$A=\ln (\bar{x})-\frac{\sum \ln (x)}{n}$.

These parameters were then used to determine the cumulative probability, which is given by

$G(x)=\int_{0}^{x} g(x) d x=\frac{1}{\widehat{\beta \Gamma(\hat{\alpha})}} \int_{0}^{x} x^{\hat{\alpha}-1} e^{-x / \hat{\beta}} d x$

Letting $t=x / \hat{\beta}$, gives rise to Eq. 11 , which is incomplete because the gamma function is undefined for $x=0$.

$G(x)=\frac{1}{\widehat{\Gamma(\hat{\alpha})}} \int_{0}^{x} t^{\hat{\alpha}-1} e^{t} d t$ 
When $x=0$, the cumulative probability distribution is

$H(x)=q+(1-q) G(x)$

where $q$ is the probability of no rainfall and can be calculated as $q=\frac{m}{n}$, where $m$ is the number of times when there is no precipitation in the time series, and $n$ is the total number of observations.

The cumulative probability, $H(x)$, is then transformed to the standard normal random variable $Z$ with mean zero and variance of one, which is the value of the SPI. The computation of the SPI was done using

$S P I=\left\{\begin{array}{l}-\left(t-\frac{c_{0}+c_{1} t+c_{2} t^{2}}{1+d_{1} t+d_{2} t^{2}+d_{3} t^{3}}\right) \text { for } 0<H(x) \leq 0.5 \\ +\left(t-\frac{c_{0}+c_{1} t+c_{2} t^{2}}{1+d_{1} t+d_{2} t^{2}+d_{3} t^{3}}\right) \text { for } 0.5<H(x) \leq 1.0\end{array}\right.$

where $t$ is determined as

$t=\left\{\begin{array}{c}\sqrt{\ln \left(\frac{1}{(H(x))^{2}}\right)} \text { for } 0<H(x) \leq 0.5 \\ \sqrt{\ln \left(\frac{1}{(1.0-H(x))^{2}}\right)} \text { for } 0.5<H(x) \leq 1.0\end{array}\right.$

and the coefficients as defined by Edwards and Mckee [50] are $c_{0}=2.515517, c_{1}=0.802853, c_{2}=0.010328$, $d_{1}=1.432788, d_{2}=0.189269$ and $d_{3}=0.001308$.

In this study the SPI program recommended by the WMO [18] was used and is freely available from the National Drought Mitigation Center at http://drought.unl. edu/MonitoringTools/DownloadableSPIProgram.aspx. The program was designed to execute multiple number of SPI monthly intervals, up to six different intervals at a time [51].

The SPI method classifies droughts when the index value is equal to or below-1.0. Meteorological droughts comprise of moderately dry, severely dry and extremely dry events. Similarly, the wet events consist of extremely wet, very wet and moderately wet events (Table 2 ). The preferred length of the time series is 50-60 years (or more) or a minimum time period of 20-30 years of monthly data [18].

Table 2 SPI classification values based on McKee et al. [70]

\begin{tabular}{ll}
\hline SPI value & Description \\
\hline $2.0+$ & Extremely wet \\
1.5 to 1.99 & Very wet \\
1.0 to 1.49 & Moderately wet \\
-0.99 to 0.99 & Near normal \\
-1.0 to -1.49 & Moderately dry \\
-1.5 to -1.99 & Severely dry \\
-2 and less & Extremely dry \\
\hline
\end{tabular}

The SPI can be used for estimating dry and wet conditions for multiple time scales varying from 1 to 72 months, however, for practical purposes based on the length of the available data, 1-24 months is the most suitable range [18]. It has been seen that SPIs short intervals, 1-6 months are relevant to meteorological droughts and soil moisture content whereas long intervals, that is, from 6 months up to 24 months or longer, provide information on streamflow, reservoirs and groundwater [18]. Thus varying the time scales can provide some insights into the different categories of droughts. These categories are meteorological, hydrological, agricultural or socioeconomic droughts. A meteorological drought describes a time period with a below average rainfall; hydrological droughts occur when there is a deficit in rainfall which affects the sub-surface moisture, surface water reservoirs and ground water; while agriculture droughts are classified when the soil moisture is low and has a negative impact on crops; and a socioeconomic drought occurs when a commodity is affected by drought conditions and there is insufficient product to meet the demand $[52,53]$.

For the area of interest, the common intervals 3, 6 and 12 months are not best suited. For Trinidad and Tobago, according to the Trinidad and Tobago Meteorological Service "Dry spell and meteorological drought policy" the 2-month SPI can be used to determine the onset, duration and severity of a dry spell and a meteorological drought [34]. In the description of the drought event, the onset occurs when the SPI is continuously negative and reaches an intensity of -1.0 or less. The duration of the drought refers to the number of months of the event while the severity is the peak SPI within the months of the drought event. To appreciate the seasonal SPI pattern, two time series were created. The 5-month SPI for the dry season period which represents the rainfall during January to May and the 7-month SPI for the wet season that is June to December were established. Hence, the time scales analyzed were 2-, 5-, 7- and 12-months, which will henceforth be referred as 2-M, 5-M-dry, 7-M-wet and 12-M respectively.

For identification of dry and wet years at each station, the SPI time series was sorted based on years and months in which a drought event occurred. Events in which the SPI value was less than -1 for two consecutive months were considered a meteorological drought and the drought ended when the SPI value was positive. The magnitude of the drought is the positive sum of the SPI for all months within the drought event [18].

\subsection{Spatial analysis (principal component analysis)}

The principal component analysis (PCA) is a standard statistical method to reduce inter-correlated variables 
into a few linearly uncorrelated ones [54]. In the determination of co-variability of droughts, that is, areas with similarities and differences of drought patterns, the principal component analysis (PCA) was applied only to the 12-M time series. As noted in Raziei et al. [27], in cases where water is managed according to the calendar year, without focusing on the seasonal variability, inter-annual variability is accounted for with the application of the 12-M time scale. We thus concentrated on the spatial variation of the 12-M SPI in the island of Trinidad with thirteen stations situated in the north and central regions.

A data matrix was set up with the observations in the rows and the stations in the columns. The SPI 12-M data matrix was subjected to (1) the Kaiser-Meyer-Olkin (KMO) [55] test which determines the sampling adequacy, that is, if the sample size is sufficient for further analysis, and (2) the Bartlett's test [56] which checks for equal variances and reveals if the data are suitable for reduction. The PCA was used with the covariance matrix, which allocate more weight to the variables with higher variances, to calculate the principal components and the eigenvalues. However, to identify the localized spatial patterns, the principal components were rotated. The North et al. [57] rule of thumb and the scree plot were utilized to determine the number of loading to retain for rotation. These methods have also been utilized by Raziei et al. [27], Santos et al. [49], Gocic and Trakovic [44] and Zhipeng et al. [58] in understanding drought patterns.

\section{Results}

\subsection{Descriptive statistics and rainfall trends for monthly, seasonal and annual time scales}

The annual average precipitation for Trinidad for the period 1980 to 2014 over the 13 rainfall stations was $2316 \mathrm{~mm}$, ranging from $1608 \mathrm{~mm}$ at La Regalada to a maximum of $3183 \mathrm{~mm}$ at Cray Fish, with a standard deviation of $578 \mathrm{~mm}$ (Fig. 3). For Trinidad November accounted for $13.5 \%$ of the total annual rainfall while March received the least monthly rainfall contributing to $2.6 \%$ of the total annual rainfall. Similarly, for Crown Point, Tobago, November accounted for $14.5 \%$ of the total annual rainfall while March received the least monthly rainfall contributing to $2.7 \%$ of the total annual rainfall. The coefficient of variation reveals that there was lower variability during the months of the wet season as compared with those of the dry season for both Trinidad and Tobago separately. The month with the greatest variability was March while the months with lowest variability were August and September. For Trinidad (Tobago) the dry season received on average about $27.3 \%$ (26.7\%) of total annual precipitation compared to the wet season with about $72.7 \%$ (73.3\%) of rainfall (Fig. 3).

Monthly, seasonal and annual precipitation values were analyzed for statistical significant monotonic trends using the Mann-Kendall test and the Sen's estimator for the magnitude of the slope for all 14 stations datasets over the 35 years. There were two decreasing trends, one
Fig. 3 Average monthly rainfall over Trinidad with the standard deviation for the 13 rainfall stations for 35 years (1980-2014)

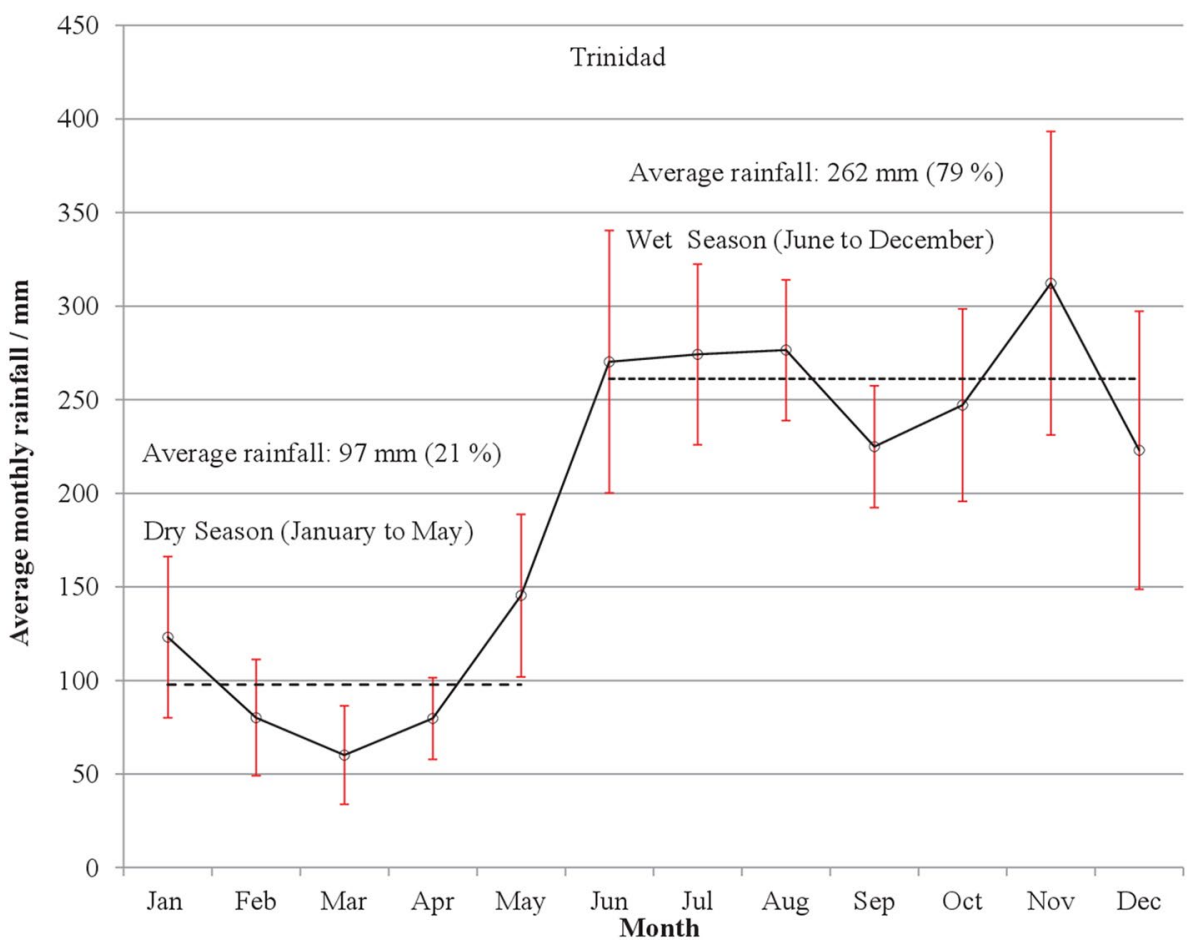

SN Applied Sciences A SPRINGER NATURE journal 
at Newlands Estate $(-1.44 \mathrm{~mm}$ per year) and another at Navet ( $-2.65 \mathrm{~mm}$ per year), while an increasing trend of $0.64 \mathrm{~mm}$ per year was observed for Tobago, Crown Point. In the following description of the statistical significant trends, the magnitudes of the trends are in the parentheses with units of $\mathrm{mm}$ per year. For the monthly, seasonal and annual time scales, there were no trends at the River Estate and UFS rainfall stations. Decreasing trends were found at UWI during the month of July $(-2.44)$ and the wet season (-1.04); at Grosvenor Estate, Newlands Estate, Cray Fish and El Susan during September $(-3.85,-3.92,-4.47$ and -3.88 respectively); and at Navet during the months of July (-4.45), August (-3.33) and September (-7.15), the annual $(-31.06)$ and the wet season $(-3.75)$. On the other hand, increasing trends in Trinidad, were found at Piarco, in March (0.67); at Navet Presbyterian, in April (2.15); at Valencia Range, in March (1.75), April (2.91) and the dry season (2.47); at Hollis Reservoir and El Susan, in April (2.91 and 2.09); at La Regalada, in January (1.81) and March (0.88). In addition, at Crown Point, Tobago there were increases during March (1.18), October (2.24) and the dry season (1.36).

\subsection{Individual years with dry events}

In the identification of meteorological droughts, it was observed that the months with missing values corresponded to drought events. The rainfall patterns for Trinidad, as seen in Sect. 4.1, vary among the stations. In order to avoid the false identification of droughts, SPI values were omitted from the time series rather than filling the missing data. The following describes how the records were omitted: for the 2-M SPI, the flagged month with the missing data and the month after were removed; as for the 12-M SPI, any twelve month period in which there were more than 2 months of missing values, that period was disregarded; for the seasonal SPI time series, that is 5-M-Dry and 7-M-Wet, if there were more than 1 month of missing values, the entire season was deleted. In this study the number of stations with no missing data for the 2-M SPI were six, for the 12-M SPI, seven, for the 5-M-Dry ten and for the 7-M-Wet eight.

For the 2-M SPI, eleven rainfall stations in the year 1987 experienced short term drought conditions with magnitudes ranging from 2.2 (River Estate) to 9.0 (Hollis). Other years in which short term drought events occurred were 1989 (11), 1995 (10) and 2001(9), with the number of stations which experienced similar drought conditions in parentheses. These meteorological droughts occurred in the months of the dry season with the exception of the drought events in 1989, which were primarily observed during the months of July, August and September.
The calculated 12-M SPI revealed that the most widespread meteorological drought was experienced in 2009-2010 at 9 stations: UWI, Piarco, Grosvenor Estate, Valencia Range, Hollis, Navet, UFS, La Regalada and Crown Point. The duration of these droughts varied among the locations. The shortest drought period was 3 months (February to April in 2010) at Crown Point, Tobago to 14 months at La Regalada, which started in November 2009 and ended in December 2010. In 2001-2002 and 1993, 7 stations experienced meteorological droughts, which began between August to November and lasted between 4 to 7 months. Drought conditions in both in 1993 and 2001-2002 were observed at six out of these seven stations. No drought events were observed for the 12-M SPI for the period of study at River Estate and EI Susan.

For the dry season ten stations were found to have experienced droughts in 2014. Other years in the dry season with meteorological droughts were 1995 (8), 2001 (8) and 1987 (7), with the number of stations which experienced drought conditions in parentheses. Given that precipitation in the wet season is responsible for about $79 \%$ of the annual rainfall in Trinidad, it is of importance to understand the changes, if any. For the wet season, the years with meteorological droughts were 2009 (10), 1985 (5), and 1997, 2002, 2012 (4), with the number of stations which experienced drought conditions in parentheses.

\subsection{Frequency of dry and wet years for Trinidad}

The 12-M SPI time series for the thirteen rain gauge stations in Trinidad for the period 1980-2014 were used for the illustration of the frequencies of occurrence of dry and wet conditions. The frequency of the dry (wet) conditions was expressed as a ratio of the number of dry (wet) events and the total number of events. In this study a dry year was defined as having an average $12-\mathrm{M} \mathrm{SPI} \leq-1.0$ and a wet year as $12-\mathrm{M} \mathrm{SPI} \geq 1.0$.

The frequency of occurrence of dry years ranged from 0.6 to $16.9 \%$ (Fig. $4 a$ ) where the $16.9 \%$ occurred at Piarco, followed by two of Trinidad's dam sites, Hollis and Navet with frequencies of 15.9 and $15.7 \%$ and the lowest at River Estate. For wet years the frequencies of the occurrence were 12.7-17.4\% (Fig. 4b). The Navet Presbyterian station recorded the least number of wet events while the highest number was observed at the Hollis reservoir.

A closer inspection into 10-year periods showed that there were variations in the frequency of occurrence of dry events. The decadal comparison of 1981-1990 and 2001-2010 revealed that the frequency of dry events at Hollis decreased from $25 \%$ in the 80 s to $15.8 \%$ in 2001-2010. As for Navet over the same period, there was an increase from 1.7 to $26.9 \%$. For wet events over 

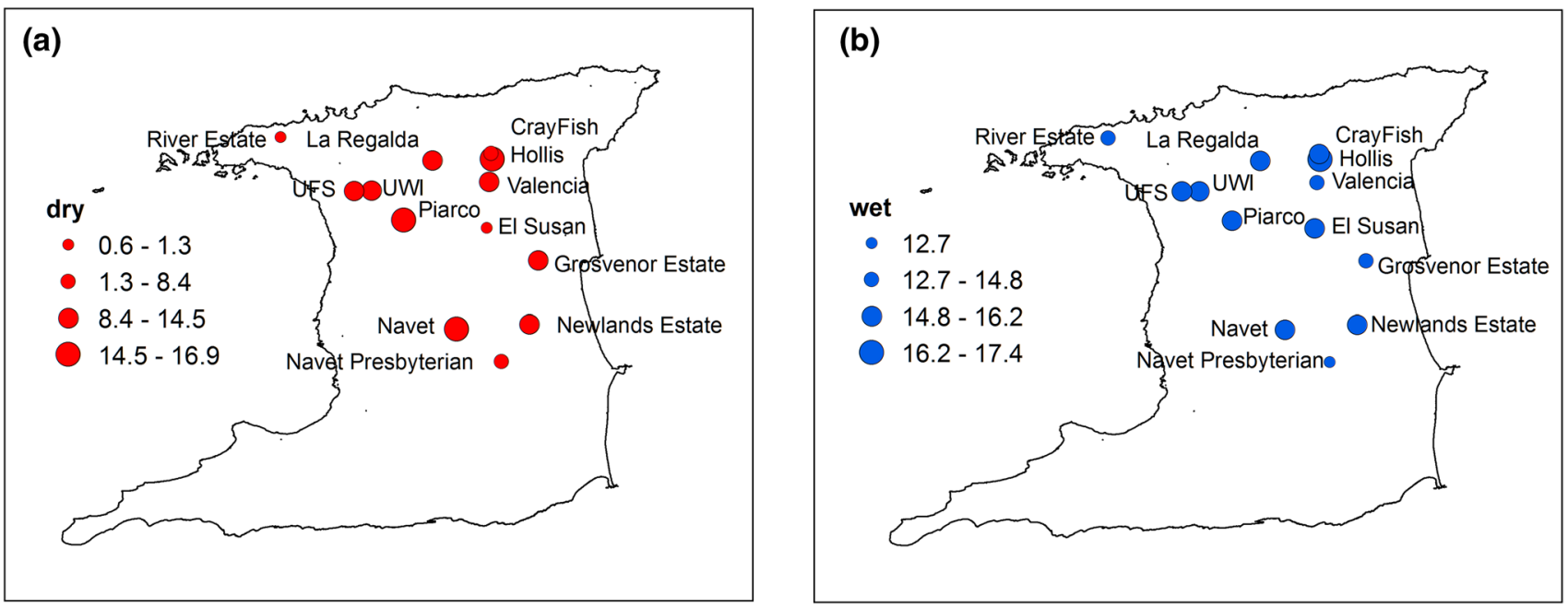

Fig. 4 a 12-M SPI frequencies of occurrence of dry years and b 12-M SPI frequencies of occurrence of wet years in Trinidad (1980-2014)

the three decades, there was a decrease in frequency of occurrence from $39.2 \%$ in $1981-1990$ to $0 \%$ in 2001-2010 at Navet, whereas for Hollis there appears to be no change in the frequency of occurrence. For Trinidad the greatest number of wet events occurred during 1981-1990 decade.

It is worth noting that for the 2001-2010 decade at Navet, Newlands Estate and Navet Presbyterian the least wet events were observed and these stations belong to the catchment area of one of the islands' surface water reservoirs, Navet Dam.

\subsection{Temporal SPI trends}

The Mann-Kendall test was employed to analyze the monotonic trends for the SPIs for time scales 2-M, 12-M, 5-M-Dry and 7-M-Wet. In the short term, there were decreasing trends in 2-M SPI at UWI, Newlands Estate and Navet while at Valencia Range and Crown Point the trends were increasing. The magnitudes of the decreasing trends ranged from 0.01 to 0.03 per year and the magnitudes of the increasing trends were between 0.08 and 0.11 per year. For all the other stations, there were no statistical significant trends (Table 3). In the long term there were five stations; UWI, Piarco, Grosvenor Estate, Newlands Estate and Navet, with decreasing 12-M SPI trends and two stations, Valencia Range and Crown Point in Tobago with increasing trends. Seasonally, for the dry season, 5-M-Dry, there were increasing trends for Valencia Range and Crown Point. For the wet season, 7-M-Wet, there was a statistical significant decreasing trend at Navet reservoir.

\subsection{Spatial variability of SPI}

In the identification of spatial patterns of meteorological droughts in Trinidad for the period 1980-2014 the 12-M SPI time series were analyzed. To measure the sampling adequacy and the sphericity of the time series the Kaiser-Meyer-Olkin (KMO) and the Bartlett's tests were applied. The KMO value was 0.76 and according to Gocic and Trakovic [44], KMO values $>0.5$ suggest that the selected data are adequate for the PCA. The Bartlett's test $p$ value was $<0.0001$ at a significance level of 0.05 , which implied that at least one of the correlations between the variables was significantly different from zero and hence the data can be used in the PCA.

Figure 5 illustrates the scree plot for the thirteen eigenvalues for the 12-M SPI with the corresponding error bars at $5 \%$ significance level. According to North's rule of thumb [57] and the inspection of the scree plot of the eigenvalues, the first two principal components (PCs) were selected for the rotation to achieve more stable spatial patterns.

Table 4 summarizes the variances of the un-rotated and rotated principal components. The results for the 12-M SPI showed that the first un-rotated principal component had the largest variance with a value of $46.32 \%$ and the cumulative variance percentage was $59.28 \%$. It was found that the cumulative variance of the rotated components remained the same with respect to the unrotated variance.

The scatter plot of the correlations between the stations (variables) and principal components after the rotation, where D1 and D2 are the first and second principal components after rotation, respectively, for the 12-M SPI is shown in Fig. 6. Each variable is a point whose coordinates are given by the loadings on the principal components. The 


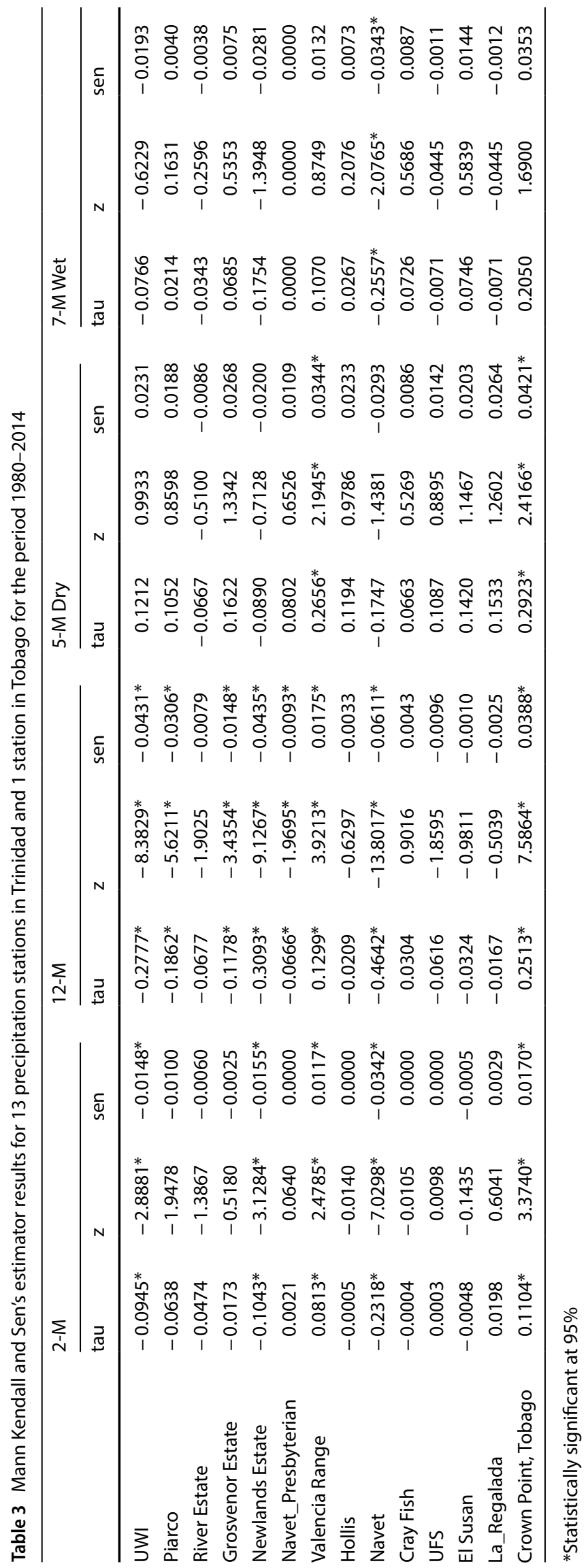


Fig. 5 Scree plot for thirteen eigenvalues and the corresponding error bars at $95 \%$ confidence level for the 12-M SPI principal components
6.0

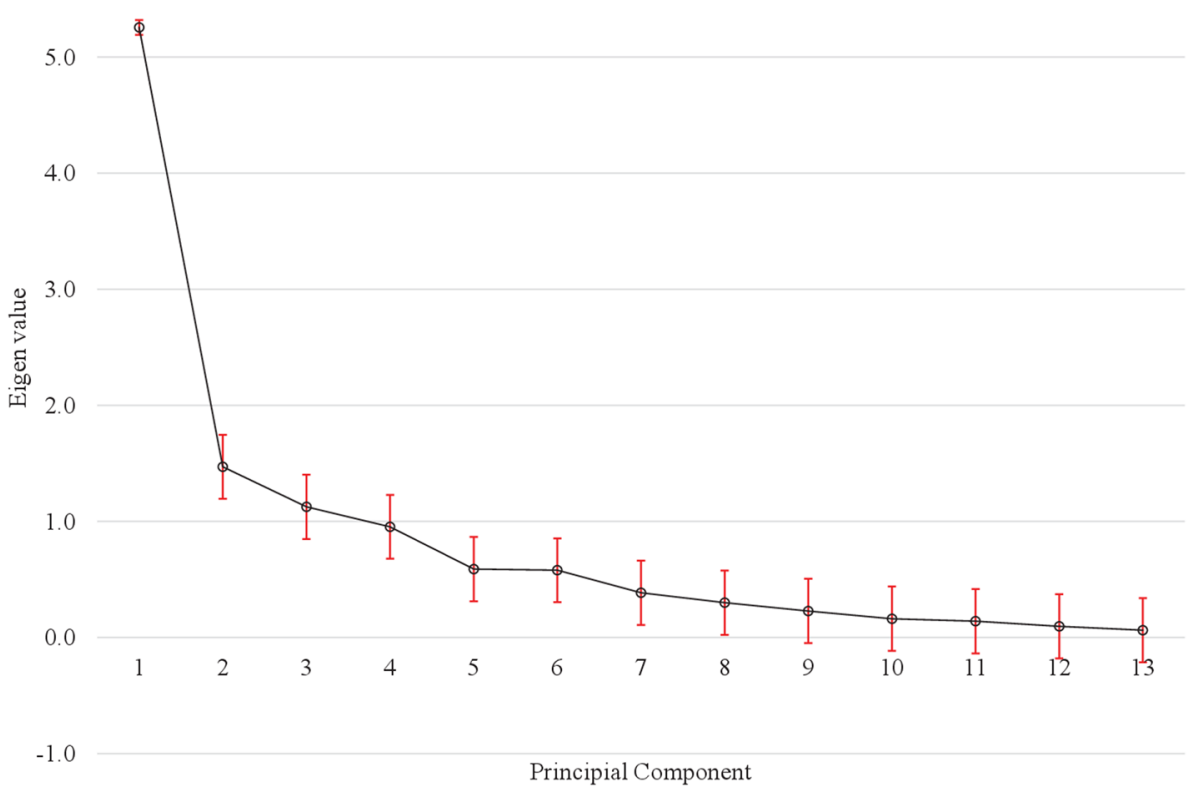

Table 4 The variances of the un-rotated and rotated principal components

\begin{tabular}{llll}
\hline Principal component & Eigenvalue & $\begin{array}{l}\text { Un- } \\
\text { rotated } \\
\text { variance }\end{array}$ & Rotated variance \\
\hline PC1 & 5.256 & 46.322 & 38.255 \\
PC2 & 1.471 & 12.959 & 21.026 \\
Cumulative percentage & 6.727 & 59.281 & 59.281 \\
\hline
\end{tabular}

correlation for the 12-M SPI indices was positive with the exception of two stations, La Regalada and Valencia Range. The loadings after the rotation provided more localized areas of drought variability. It was observed that after the rotation, the total variance was evenly explained by the two rotated principal components (RPCs), while the cumulative variance was negligibly changed with respect to the un-rotated case.
Fig. 6 Scatter plot of the correlations between stations and principal components after the rotation for the 12-M SPI

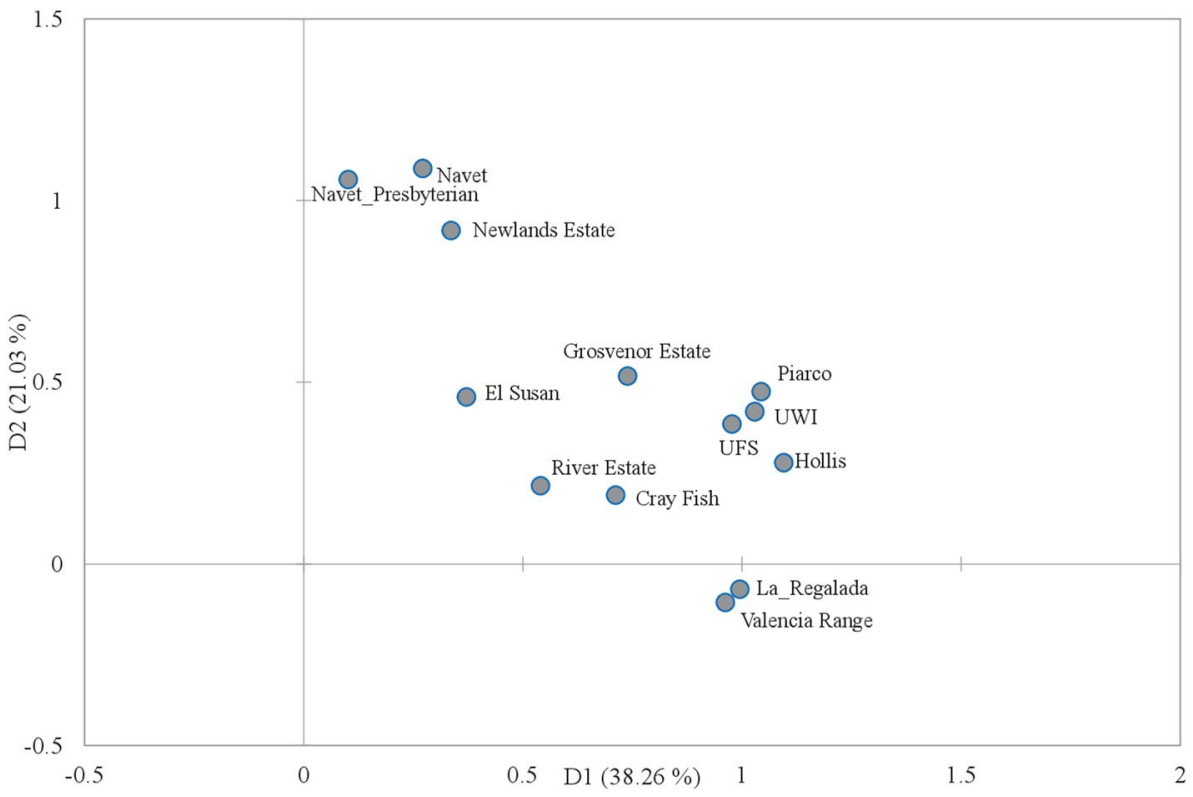

SN Applied Sciences 

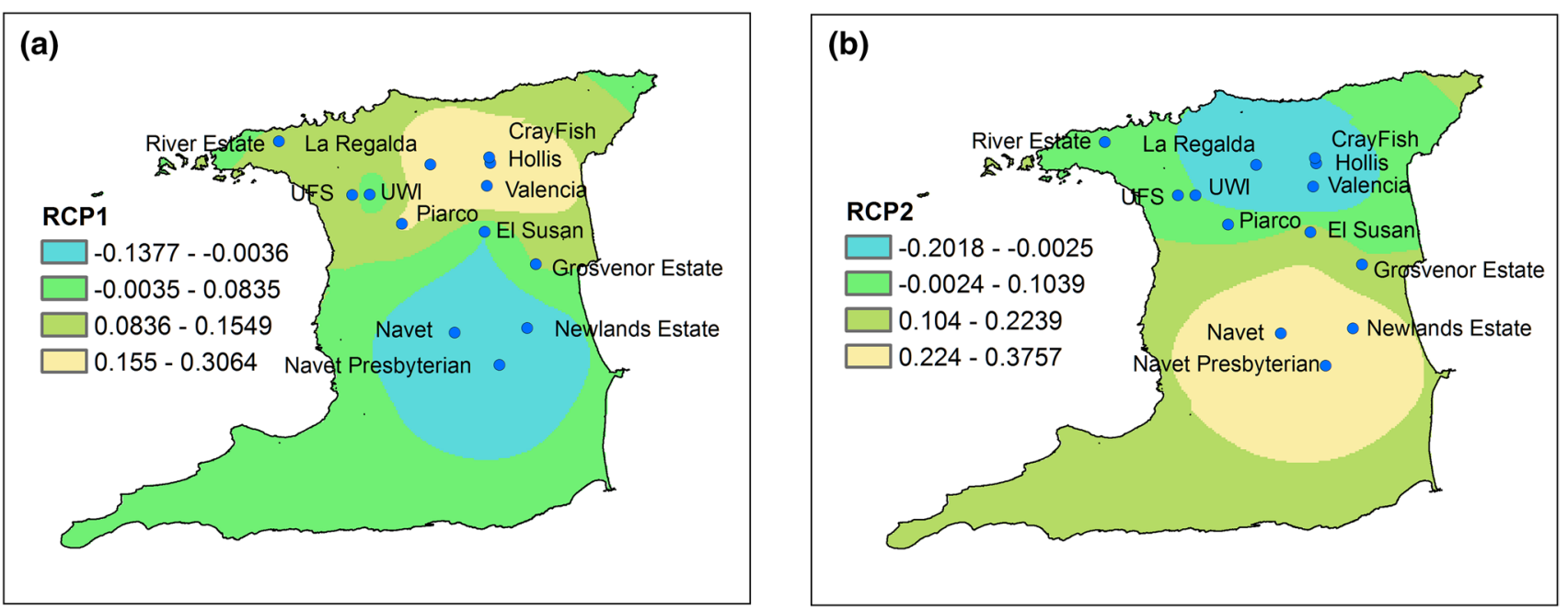

Fig. 7 Distribution of 12-M SPI the rotated loadings for the first two principal components (RPC1 and RPC2)

The spatial patterns of the rotated principal component loadings, RPC1 and RPC2, 12-M SPI for the period 1980-2014 are shown in Fig. 7. These RPCs revealed four distinct sub-regions, characterized by different drought variability. The distinct sub-regions identified are (1) the center of the Northern range, which includes the Hollis reservoir and the Piarco stations, (2) the center of the central range, in which the Navet reservoir belongs, (3) the remaining area of the Northern range and the Caroni Basin, and (4) the southern part of the island.

\section{Discussion}

Despite the small surface area of $4826 \mathrm{~km}^{2}$ for Trinidad, the precipitation trend analysis revealed that there were variations over time and differences among the magnitude of the trends, at the various locations. The increasing trends indicated a larger volume of rainfall recorded at the particular location and vice versa for decreasing trends. The results suggest rainfall spatial variability over the northern and central regions of Trinidad.

The SPI was employed on the short scale, 2-M; long scale, 12-M; and seasonal scales; $5-M$ and 7-M. The influence of the deficit of rainfall may impact a number of sectors. On the 2 month temporal scale, the WMO suggests drought conditions can adversely affect the agriculture sector [18]. In our study, one of the most wide-spread droughts for the 2-M time scale in north and central Trinidad was experienced in 1989, during the dry season. Many of the farmers in Trinidad utilize water from the rivers for irrigation of their crops [59]. We therefore note that meteorological droughts during the months of January to May can affect the farmers in the agriculture sector. In Poland it was observed that agricultural drought development is reflected at the 1-3 month SPI [60], and in Europe the 3 month SPI links to crop vegetation stress [61] which agrees well with WMO's statement on the impact of drought on the agriculture sector [18].

The 12-M SPI results suggest that although Trinidad has a relative small land surface there is variability in the duration and magnitudes meteorological droughts. According to WMO [18], SPI at the 12-month time-scale reflects longterm precipitation patterns and can impact on the hydrological sector. We note here that for our study, meteorological droughts were identified at the 12-M scale in 2010, 2001-2002, 1993. The wider Caribbean also experienced drought conditions in 2009-2010 [5].

Information form WASA shows surface water levels at the four main reservoirs in Trinidad and Tobago in 2001 and 2010 were lower than the 1984-2014 average lake levels, indicating water stress and hence a suspected hydrological drought [6]. Future studies can therefore utilize SPI values to investigate their use as an indicator for hydrological droughts in Trinidad and Tobago. Gocic and Trajkovic [62] stated that the 12-M SPI can be useful for planning the efficient management of water resources and further work may involve the development of an information system for early drought warning and monitoring.

Normally, hydrological drought indices use streamflow because it is the most measured or of most interest to water resources managers, however, other variables such as groundwater levels and lake levels can also be utilized [63]. Now comparing the SPI results to water levels at two dam sites, we see that in 2001 for Navet and Hollis, the 5-M-Dry SPIs were moderately and severely dry with peak values being -1.4 and -1.61 , respectively. We therefore looked at the lake levels at the two of the reservoirs during 
the time of the meteorological drought. The monthly water levels for 2001, at the Hollis and Navet reservoirs were at the maximum level in January, which was the same as the average lake level for the period 1984 to 2014. During the months of February and November, the 2001 water level was lower than the average. However, at the end of December the Hollis reservoir was recharged to the maximum reservoir level. As for Navet Dam, at the end of December the water level was the below the 1984-2014 average. It is noteworthy to state that reservoir levels are affected by other factors such as the amount of water withdrawn to meet demand and climatic parameters of temperature, relative humidity and wind speed. Nevertheless, the meteorological drought in 2001 and the observed low water levels in two of the islands three main dams in 2001 may be more than a coincidence. Maccioni et al. [64] stated that 12-M SPI is a weak indicator to represent the levels of Lake Trasimeno, Italy. Additionally, Valigi et al. [65] found a significant relationship between the 12-M SPI and the fluctuations of the lake levels, stating that 12-M SPI can be a useful indicator to represent drought severity, by considering the lake level fluctuations rather than the lake level. Hence, further work into lake level fluctuations and droughts can be done to determine whether there is any relationship in Trinidad and Tobago.

Considering the occurrences of meteorological drought on a seasonal basis we observe that there was a higher occurrence during the dry season compared with the wet season (Table 3). In our study the greater occurrence of droughts in the dry season may add to stresses on water availability not only for residential, commercial and industrial demand but also for agriculture. If in the future, there is an increase in occurrence of droughts in the dry season in Trinidad, then mitigation measures will be required. For a similar small tropical island in the Pacific, Fiji, it was found that drought occurrences may become more common in the future [66]. Further work on future projections of occurrence of droughts for Trinidad and Tobago would be recommended. In addition to identifying the time the meteorological drought occurred for the different time scales, the SPI analysis revealed that all the stations in this study did not reflect the same drought severity and magnitude. This observed drought variability over the study area of the small island of Trinidad suggests the need for spatial analysis of droughts as indicated by the IPCC 5 th Assessment Report, Small Islands Chapter [2].

Over the 35 year period studied, the frequency of the meteorological droughts decreased at the Hollis Reservoir, while at the Navet Reservoir there was an increase. Decreases in frequency of the 12-M SPI meteorological droughts imply that there may be more normal conditions. On the other hand, increases in droughts may indicate water stress. The temporal SPI trends for both the 2-M and 12-M SPIs at the 14 locations differed both in direction (increasing and decreasing) and magnitude (Table 3). There were more locations affected by the 12-M meteorological drought and with larger changes. The observed decreasing trends for the 2-M trend varied from 0.01 to 0.03 per year while $12-M$ trends extended from 3.43 to 13.80 per year (Table 3). There were increasing trends for two stations, one in Trinidad and one in Tobago, with rates at 0.01 and 0.02 per year for the 2-M SPI, and 0.02 and 0.04 per year for the 12-M SPI. The larger the magnitude of change estimated by the Sen Estimator suggests the more severe the meteorological drought might be and hence the greater the potential impact. Comparing our findings on SPI trends, we see that in Hunan Province, China there were different trends both spatially and temporally [67]. In addition, for Madeira, a small tropical island of area $741 \mathrm{~km}^{2}$, it was found that on the SPI 6-month scale, there were variations of meteorological droughts duration, magnitude and frequency, similar to that of our results [68]. These results, therefore emphasize the variations of droughts on small islands and support the need for more individual island studies as recommended by [2]. Overall, the temporal SPI trends in Trinidad are mainly pointing towards more drought conditions which agrees well with Mc Lean et al. [17] findings for the projected increase in the number of consecutive dry days under the B2 scenario over Trinidad from their regional study.

The observed variation in patterns of drought occurrence and magnitude as interpreted from the results of the monotonic trend analyses has implications at the dam sites with high importance to water resources. That is, at Hollis Dam for the period 1980-2014 there were no changes while at the Navet Dam there were decreasing SPI trends for the 2-M, 12-M and 7-M Wet. These observed trends, mainly the 12-M and 7-M Wet are one of many factors that can affect the available water at the reservoirs. Navet is the second largest surface water resource that is used to meet Trinidad's water demand. Negative SPI trends at Navet imply a drying pattern, thus possible adverse effects on the water resources of Trinidad.

Our results indicate that the frequencies (Fig. 4) and trends (Table 3) for the Piarco time series are not representative of the conditions at the Navet and Hollis dam sites. The Piarco station is located at the International Airport and the dataset is freely available on the Trinidad and Tobago Meteorological Services website via http:// metoffice.gov.tt/climate_daily_data. Hence, the use of the Piarco precipitation data for hydrological studies may not be entirely representative of the rainfall patterns at dam sites. As such, caution should be exercised in using these Piarco precipitation data to represent conditions at dam sites in Trinidad. 
The rotated principal component analysis on the 12-M SPI identified three sub-regions for Trinidad (Fig. 7). Each of these sub-regions represents different drought variability and has varying rainfall totals. These different rainfall patterns are characteristic with these sub-regions identified which may be influenced by the local topography and landscapes [44]. It must be noted that the sub-regions represent the spatial drought variability for the period 1980-2014. The north-eastern region where Crayfish and Hollis are located receives the largest amount of annual precipitation. Given that the southern region of the island was not represented by in situ data the southern subregion therefore cannot accurately reflect the drought conditions.

In this study, there were temporal and spatial variability within the northern and central regions of the small Caribbean island of Trinidad. In addition, these results also suggest that when investigating and planning efficient water resources management under the back-drop of climate change/variability, drought sub-regions should be identified to be included in such studies. In the Caribbean region Peterson et al. [69] noted that there are correlations between the Caribbean rainfall and Equatorial Pacific Sea Surface Temperatures Anomalies (SSTAs) while Stephenson et al. [10] suggested that the Atlantic Sea Surface Temperatures (SST) and the Atlantic multi-decadal oscillation (AMO) may be attributed to the variability in temperature and precipitation extreme events and further noted the need for further investigations. Acknowledging that the changes in the rainfall patterns in the Caribbean region are heterogeneous and noting that within the small island of Trinidad there is variation in meteorological droughts, then there may be a need to better understand the teleconnections between Trinidad's meteorological droughts and the large scale climate factors for developing droughts mitigation measures.

\section{Conclusion}

It may be suggested that the results of this study of the assessment of meteorological droughts within northern and central regions of Trinidad using 13 datasets be used as a baseline for establishing drought mitigation measures in this small island state. Noteworthy, is the fact that the precipitation times series with missing data may lead to false identification of droughts, if not addressed. Wide spread meteorological droughts were identified, in the short term, that is the 2-M SPI, in 1987, 1989 and 1995, and for the long term (12-M SPI) in 2009-2010, 2001-2002 and 1993. Some of the meteorological droughts identified may have impacted on the agricultural and hydrological sectors. Seasonally, more droughts occurred in the dry season compared with the wet season implying there could be more severe consequences in the dry seasons. On the decadal time scale there are signs of positive impact on the water resources at Hollis Reservoir and a negative impact at the Navet Dam. Overall, concern is raised for the Navet area due the SPIs temporal and spatial variations. Spatially, three distinct areas of drought variability were identified from the principal component analysis. Caution should therefore be exercised in using readily available Piarco precipitation data to represent conditions at dam sites in Trinidad. The results from this study may also be used as inputs for climate impact and projections studies for this island state in the Caribbean. Similar analyses to understand the spatio-temporal variability of extreme weather events on individual islands in the Caribbean may yield useful information.

Acknowledgements We would like to acknowledge and thank the Water Resources Agency of Trinidad and Tobago (WRA), the Meteorological Service of Trinidad and Tobago (MET) and the University of the West Indies, St Augustine Campus for making datasets available. This research did not receive any specific grant from funding agencies in the public, commercial, or not-for-profit sectors. The authors are grateful to the reviewers for their valuable comments and suggestions made towards improving the quality of the manuscript.

\section{Compliance with ethical standards}

Conflict of interest The authors declare that they have no conflict of interest.

\section{References}

1. Glotzbach R (2016) In an uncertain world, planning for floods and droughts is critical. International Water Association. https ://iwa-network.org/in-an-uncertain-world-planning-for-flood s-and-droughts-is-critical. Accessed 01 Aug 2019

2. Nurse, LA, McLean RF, Agard J, Briguglio LP, Duvat-Magnan V, Pelesikoti N, Tompkins E, Webb A (2014) Small islands. In: Change Barros VR, Field CB, Dokken DJ, Mastrandrea MD, Mach KJ, Bilir TE, Chatterjee M, Ebi KL, Estrada YO, Genova RC, Girma B, Kissel ES, Levy AN, MacCracken S, Mastrandrea PR, White LL (eds) Climate change 2014: impacts, adaptation, and vulnerability. Part B: regional aspects. Contribution of working group II to the fifth assessment report of the intergovernmental panel on climate. Cambridge University Press, Cambridge, pp 1613-1654

3. Nabaei S, Sharafati A, Nabaei S, Yaseen ZM, Shahid S (2019) Copula based assessment of meteorological drought characteristics: regional investigation of Iran. Agr For Meteorol 276-277:1-10. https://doi.org/10.1016/j.agrformet.2019.06.010

4. The Food and Agriculture Organization of the United Nations (FAO) (2019) The Caribbean must prepare for increased drought due to climate change. FAO Regional Office for Latin America and the Caribbean. http://www.fao.org/americas/noticias/ver/ en/c/419202/. Accessed 01 Aug 2019

5. Caribbean Institute for Meteorology and Hydrology (CIMH) and The Food and Agriculture Organization of the United Nations (FAO) (2016) Drought characteristics and 
management in the Caribbean. http://www.fao.org/3/a-i5695 e.pdf. Accessed 01 Aug 2019

6. Llanos A (2010) WASA tightens water usage. Trinidad and Tobago Guardian. http://www.guardian.co.tt/article-6.2.33079 9.92c1562a57. Accessed 14 Aug 2019

7. The Water and Sewerage Authority of Trinidad and Tobago (WASA) (2015) WASA encourages water conservation in view of a dry wet season. http://www.tema365.com/web/wp-conte nt/uploads/2016/02/TempWaterSupplySchedule-Tobago2015 Oct.pdf. Accessed 25 May 2016

8. The Water and Sewerage Authority of Trinidad and Tobago (WASA) (2019) Water restriction \& schedules remain in effect. https://www.wasa.gov.tt/AdPress_2019-05-29_RestrictionsInE ffect.html. Accessed 01 Aug 2019

9. Jury M, Malmgren BA, Winter A (2007) Subregional precipitation climate of the Caribbean and relationships with ENSO and NAO. J Geophys Res Atmos 112:D16107. https://doi. org/10.1029/2006JD007541

10. Stephenson TS, Vincent LA, Allen T, Van Meerbeeck CJ, McLean $\mathrm{N}$, Peterson TC, Taylor MA, Aaron-Morrison AP, Auguste T, Bernard D, Boekhoudt JR (2014) Changes in extreme temperature and precipitation in the Caribbean region, 1961-2010. Int J Climatol 34(9):2957-2971. https://doi.org/10.1002/joc.3889T

11. Trinidad and Tobago Meteorological Services (MET) (2019) Climate: trends. https://www.metoffice.gov.tt/Climate. Accessed 02 Apr 2019

12. Singh $B$ (1997) Climate-related global changes in the southern Caribbean: Trinidad and Tobago. Glob Planet Change 15(34):93-111. https://doi.org/10.1016/S0921-8181(97)00006-4

13. Stone RJ (2001) Changing seasonal rainfall patterns in Trinidad: myth or reality? West Indian J Eng 23(2):9-16

14. Beharry SL, Clarke RM, Kurmarsingh K (2014) Precipitation trends using in situ and gridded datasets. Theor Appl Climatol 115(3-4):599-607. https://doi.org/10.1007/s0070 4-013-0921-1

15. Beharry SL, Clarke RM, Kumarsingh K (2015) Variations in extreme temperature and precipitation for a Caribbean island: Trinidad. Theor Appl Climatol 122(3-4):783-797. https://doi. org/10.1007/s00704-014-1330-9

16. Campbell JD, Taylor MA, Stephenson TS, Watson RA, Whyte FS (2011) Future climate of the Caribbean from a regional climate model. Int J Climatol 31:1866-1878. https://doi.org/10.1002/ joc.2200

17. McLean NM, Stephenson TS, Taylor MA, Campbell JD (2015) Characterization of future Caribbean rainfall and temperature extremes across rainfall zones. Adv Meteorol 9:1-18. https:// doi.org/10.1155/2015/425987

18. World Meteorological Organization (WMO) (2012) Standardized precipitation index user guide (M. Svoboda, M. Hayes and D. Wood). (WMO-No. 1090), Geneva. https://library.wmo.int/ pmb_ged/wmo_1090_en.pdf. Accessed 2 Apr 2019

19. Teodoro PE, CorrEa CCG, Torres FE, da Silva Junior CA, Gois G, Delgado RC, de Oliveira-Junior JF (2015) Analysis of the occurrence of wet and drought periods using standardized precipitation index in mato grosso do sul state, Brazil. J Agron 14(2):80-86. https://doi.org/10.3923/ja.2015.80.86

20. Huang J, Sun S, Xue Y, Li J, Zhang J (2014) Spatial and temporal variability of precipitation and dryness/wetness during 19612008 in Sichuan province, West China. Water Resour Manag 28(6):1655-1670. https://doi.org/10.1007/s11269-014-0572-8

21. Zhang Q, Xu CY, Zhang Z (2009) Observed changes of drought/ wetness episodes in the Pearl River basin, China, using the standardized precipitation index and aridity index. Theor Appl Climatol 98(1-2):89-99. https://doi.org/10.1007/s0070 4-008-0095-4
22. Edossa DC, Babel MS, Gupta AD (2010) Drought analysis in the Awash River Basin, Ethiopia. Water Resour Manag 24(7):14411460. https://doi.org/10.1007/s11269-009-9508-0

23. Livada I, Assimakopoulos VD (2007) Spatial and temporal analysis of drought in Greece using the Standardized Precipitation Index (SPI). Theor Appl Climatol 89(3):143. https://doi. org/10.1007/s00704-005-0227-z

24. Goyal MK (2014) Statistical analysis of long term trends of rainfall during 1901-2002 at Assam, India. Water Resour Manag 28(6):1501-1515. https://doi.org/10.1007/s11269-014-0529-y

25. Kattelus M, Salmivaara A, Mellin I, Varis O, Kummu M (2016) An evaluation of the standardized precipitation index for assessing inter-annual rice yield variability in the Ganges-Brahmaputra-Meghna region. Int J Climatol 36:2210-2222. https://doi. org/10.1002/joc.4489

26. Buttafuoco G, Caloiero T, Coscarelli R (2015) Analyses of drought events in Calabria (Southern Italy) using standardized precipitation index. Water Resour Manag 29(2):557-573. https://doi. org/10.1007/s11269-014-0842-5

27. Raziei T, Daryabari J, Bordi I, Pereira LS (2009) Spatial patterns and temporal trends of precipitation in Iran. Theor Appl Climatol 115(3-4):531-540. https://doi.org/10.1007/s00704-013-0919-8

28. Zarei AR (2019) Analysis of changes trend in spatial and temporal pattern of drought over south of Iran using standardized precipitation index (SPI). SN Appl Sci 1:465. https://doi.org/10.1007/ s42452-019-0498-0

29. Gunda T, Hornberger GM, Gilligan JM (2016) Spatiotemporal patterns of agricultural drought in Sri Lanka: 1881-2010. Int J Climatol 36:563-575. https://doi.org/10.1002/joc.4365

30. World Meteorological Organization (WMO) and Global Water Partnership (GWP) (2016) Integrated drought management programme handbook of drought indicators and indices. No. 1173. http://www.droughtmanagement.info/literature/GWP_Handb ook_of_Drought_Indicators_and_Indices_2016.pdf. Accessed 01 Aug 2019

31. Trotman A, Pologne L, Stoute S, Mehdi B, Senecal C, Gollamudi A (2008) A proposed approach to monitoring and assessing drought in the Caribbean. In: The second Turkey-Israel workshop on drought monitoring and mitigation, Turkey, June 16-29. https://www.mcgill.ca/cariwin/files/cariwin/Turkey-Israel-2008CDPMN.pdf. Accessed 20 June 2015

32. University Corporation for Atmospheric Research (UCAR) (2019) Climate Data Guide; Palmer Drought Severity Index (PDSI). https ://climatedataguide.ucar.edu/climate-data/palmer-droughtseverity-index-pdsi. Accessed 29 May 2019

33. National Drought Mitigation Center (2019) Drought.gov; Crop Moisture Index https://www.drought.gov/drought/data-galle ry/crop-moisture-index. Accessed 29 May 2019

34. Trinidad and Tobago Meteorological Services (MET) (2019) Climate: drought policy. http://metoffice.gov.tt/Climate. Accessed 2 Apr 2019

35. Trinidad and Tobago Water Resources Agency (WRA) (2001) Integrating the management of watersheds and coastal areas in Trinidad and Tobago. Prepared by The Water Resources Agency for The Ministry of the Environment, Complex Independence Square, Port of Spain. http://www.oas.org/reia/iwcam/pdf/trini dad\%20and\%20tobago/trinidad\%20and\%20tobago\%20nat ional\%20report.pdf. Accessed 8 July 2016

36. Trinidad and Tobago Meteorological Services (MET) (2019) Climate: Trinidad and Tobago. http://metoffice.gov.tt/Climate. Accessed 2 Apr 2019

37. Chadee DD (2009) Oviposition strategies adopted by gravid Aedes aegypti (L.) (Diptera: Culicidae) as detected by ovitraps in Trinidad, West Indies (2002-2006). Acta Trop 111(3):279-283. https://doi.org/10.1016/j.actatropica.2009.05.012 
38. Plummer N, Allsopp T, Lopez JA (2003) Guidelines on climate observation networks and systems. World Meteorological Organization. WMO/TD No. 1185

39. Frich P, Alexander LV, Della-Marta P, Gleason B, Haylock M, Tank AK, Peterson T (2002) Observed coherent changes in climatic extremes during the second half of the twentieth century. Clim Res 19(3):193-212. https://doi.org/10.3354/cr019193

40. Zhai $P$, Zhang $X$, Wan $H$, Pan X (2005) Trends in total precipitation and frequency of daily precipitation extremes over China. J Clim 18(7):1096-1108. https://doi.org/10.1175/JCLI-3318.1

41. Aziz Abdul, Omar I, Burn Donald H (2006) Trends and variability in the hydrological regime of the Mackenzie River Basin. J Hydrol 319(1-4):282-294. https://doi.org/10.1016/j.jhydrol.2005.06.039

42. Gao P, Mu XM, Wang F, Li R (2011) Changes in streamflow and sediment discharge and the response to human activities in the middle reaches of the Yellow River. Hydrol Earth Syst Sci 15(1):1-10. https://doi.org/10.5194/hess-15-1-2011

43. Thomas Jobin, Prasannakumar V (2016) Temporal analysis of rainfall (1871-2012) and drought characteristics over a tropical monsoon-dominated State (Kerala) of India. J Hydrol 534(7):266-280. https://doi.org/10.1016/j.jhydrol.2016.01.013

44. Gocic M, Trajkovic S (2013) Analysis of changes in meteorological variables using Mann-Kendall and Sen's slope estimator statistical tests in Serbia. Glob Planet Change 100:172-182. https ://doi.org/10.1016/j.gloplacha.2012.10.014

45. Shahid S (2010) Rainfall variability and the trends of wet and dry periods in Bangladesh. Int J Climatol 30(15):2299-2313. https:// doi.org/10.1002/joc.2053

46. Hirsch RM, Slack JR (1984) A nonparametric trend test for seasonal data with serial dependence. Water Resour Res 20(6):727-732

47. Helsel D, Hirsch R (2002) Statistical methods in water resources. Geological Survey, Reston, Virginia

48. Sen PK (1968) Estimates of the regression coefficient based on Kendall's Tau. J Am Stat Assoc 63(324):1379-1389

49. Santos JF, Pulido-Calvo I, Portela MM (2010) Spatial and temporal variability of droughts in Portugal. Water Resour Res. https ://doi.org/10.1029/2009WR008071

50. Edwards DC, McKee TB (1997) Characteristics of 20th century drought in the United States at multiple time scales. Climatology report no. 97-2

51. National Drought Mitigation Center (2016) Program to Calculate Standardized Precipitation Index. https://drought.unl.edu/ droughtmonitoring/SPI.aspx. Accessed 16 Dec 2016

52. Wu J, Chen X, Yao H, Liu Z, Zhang D (2018) Hydrological drought instantaneous propagation speed based on the variable motion relationship of speed-time process. Water Resour Res 54(11):9549-9565. https://doi.org/10.1029/2018WR023120

53. National Oceanic and Atmospheric Administration (NOAA) (2019) Definition of drought. https://www.ncdc.noaa.gov/monit oring-references/dyk/drought-definition. Accessed 01 Aug 2019

54. Bonaccorso B, Bordi I, Cancelliere A, Rossi G, Sutera A (2003) Spatial variability of drought: an Analysis of the SPI in Sicily. Water Resour Manag 17(4):273-296. https://doi.org/10.1023/A:10247 16530289

55. Kaiser HF (1970) A second generation little jiffy. Psychometrika 35(4):401-415

56. Bartlett MS (1954) A note on the multiplying factors for various $\chi^{2}$ approximations. J R Stat Soc Ser B 16(2):96-298

57. North G, Bell Thomas, Cahalan R, Moeng F (1982) Sampling errors in the estimation of empirical orthogonal functions. Mon Weather Rev 110(7):699-706
58. Zhipeng L, Wang Y, Shao M, Jia X, Li X (2016) Spatiotemporal analysis of multiscalar drought characteristics across the Loess Plateau of China. J Hydrol 534:281-299. https://doi. org/10.1016/j.jhydrol.2016.01.003

59. Hassanali S (2005) Water woes wiping out crops in Warrenville. Sunday Guardian. http://library2.nalis.gov.tt/gsdl/collect/news3 /index/assoc/HASH3f14/1d29e999.dir/231.jpg. Accessed 10 Aug 2019

60. Łabędzki L (2007) Estimation of local drought frequency in central Poland using the standardized precipitation index SPI. Irrig Drain 56(1):67-77. https://doi.org/10.1002/ird.285

61. Bachmair S, Tanguy M, Hannaford J, Stahl K (2018) How well do meteorological indicators represent agricultural and forest drought across Europe? Environ Res Lett. https://doi. org/10.1088/1748-9326/aaafda

62. Gocic M, Trajkovic S (2013) Spatiotemporal characteristics of drought in Serbia. J Hydrol 510:110-123. https://doi. org/10.1016/j.jhydrol.2013.12.030

63. Van Loon A (2015) Hydrological drought explained. Wiley Interdiscip Rev Water 2(4):359-392. https://doi.org/10.1002/ wat2.1085

64. Maccioniv P, Kossida M, Brocca L, Moramarco T (2015) Assessment of the drought hazard in the Tiber River Basin in Central Italy and a comparison of new and commonly used meteorological indicators. J Hydrol Eng. https://doi.org/10.1061/(ASCE) HE.1943-5584.0001094

65. Valigi D, Luque-Espinar JA, Di Matteo L, Cambi C, PardoIguzquiza E, Rossi M (2016) Analysis of drought conditions and their effects on Lake Trasimeno (Central Italy) levels. Acque Sotterranee Ital J Groundw. https://doi.org/10.7343/as-2016-215

66. Deo R (2011) On meteorological droughts in tropical Pacific Islands: time-series analysis of observed rainfall using Fiji as a case study. Meteorol Appl 18(2):171-180. https://doi. org/10.1002/met.216

67. Du J, Jian F, Wei X, Peijun S (2013) Analysis of dry/wet conditions using the standardized precipitation index and its potential usefulness for drought/flood monitoring in Hunan Province, China. Stoch Environ Res Risk Assess 27(2):377-387. https://doi. org/10.1007/s00477-012-0589-6

68. Espinoas A, Portela M, Rodrigues R (2019) Spatio-temporal variability of droughts over past 80 years in Madeira Island. J Hydrol Reg Stud. https://doi.org/10.1016/j.ejrh.2019.100623

69. Peterson TC, Taylor MA, Demeritte R, Duncombe DL, Burton S, Thompson F, Porter A, Mercedes M, Villegas E, Fils RS, Klein Tank A, Martis A, Warner R, Joyette A, Mills W, Alexander L, Gleason $B$ (2002) Recent changes in climate extremes in the Caribbean region. J Geophys Res Atmos. https://doi.org/10.1029/2002J D002251

70. McKee T, Doesken N, Kliest J (1993) The relationship of drought frequency and duration to time scales. In: Proceedings of the 8th conference of applied climatology, 17-22 January, Anaheim, CA. American Meteorological Society, Boston, pp 179-184

Publisher's Note Springer Nature remains neutral with regard to jurisdictional claims in published maps and institutional affiliations. 